\title{
AlLOZYME DIVERSITY IN THREE ENDEMIC SPECIES OF Cistus (Cistaceae) From the Canary Islands: INTRASPECIFIC AND INTERSPECIFIC COMPARISONS AND IMPLICATIONS FOR GENETIC CONSERVATION ${ }^{1}$
}

\author{
Francisco Batista, ${ }^{2}$ Angel Bañares, ${ }^{3}$ Juli Caujapé-Castells, $, 2,4$ \\ Eduardo Carqué, ${ }^{3}$ Manuel Marrero-Gómez, ${ }^{3}$ AND \\ Pedro A. SosA ${ }^{2,5}$ \\ 2Departamento de Bioloǵa, Universidad de Las Palmas de Gran Canaria, Campus Universitario de Tafira, 35017 Las Palmas, \\ Canary Islands, Spain; \\ ${ }^{3}$ Parque Nacional del Teide, Apartado de correos 1047, 38080 Santa Cruz de Tenerife, Canary Islands, Spain
}

\begin{abstract}
Patterns of variation at 13 isozyme loci were examined in 11 populations in three Cistus species strictly endemic to the Canary Islands. Cistus osbaeckiaefolius and C. chinamadensis display low levels of isozyme variation associated with moderate to high interpopulation differentiation, which probably arose through historical bottlenecks in a landscape of habitat fragmentation, grazing, and human influence. By contrast, C. symphytifolius ranks among the subset of narrow endemics with high levels of isozyme variation and features different degrees of genetic structuring that are closely associated with taxonomic ascription. Low interpopulation differentiation in var. leucophyllus is possibly a reflection of its recent origin or of moderate levels of gene flow between its populations. High interpopulation differentiation in var. symphytifolius probably arose due to slight ecological differences between populations coupled with low levels of gene flow. Interpretation of neighbor-joining trees in the light of geological data substantiates the hypothesis that C. symphytifolius (or a very close relative) might be the ancestor of the other stands of Cistus in the islands. Conservation implications of our survey are the identification of the two populations of $C$. chinamadensis with the highest allele and genotype richness for preservation on genetic grounds and advice to prevent artificial gene flow in this taxon lest it might disrupt locally adapted gene combinations. All populations of $C$. osbaeckiaefolius should be given conservation priority on ecological grounds despite their genetic depauperation.
\end{abstract}

Key words: allozymes; Canary Islands; Cistaceae; Cistus; conservation genetics; genetic differentiation; genetic variability.

The Canarian archipelago consists of seven large oceanic islands that constitute an exceptionally well-suited system to study plant speciation because the dating of their geological age facilitated by their volcanic origin permits us to assess the tempo and mode of evolutionary divergence. The Canaries exhibit a broad range of geological ages, which vary between 1 million year (my) for El Hierro and 21 my for Fuerteventura (Garcia-Talavera, 1999). Their proximity to the African continent suggests that they are reasonably accessible to colonizers and that multiple introductions may have occurred for some closely related taxonomic groups. Approximately 570 flowering plant species are endemic to the Canaries (SantosGuerra, 1999), which highlights them as one of the volcanic archipelagos with a higher incidence of endemicity. However, the high rate of evolution and speciation in these islands is also accompanied by an increased rate of extinction due to natural and anthropogenic reasons. Over $20 \%$ of all endemic plants currently described in the Canaries are endangered (Bramwell, 1990) because of either habitat loss, impact of nonnative animals and plants, or fragmentation in small disjoint populations (Ayensu, 1983; Brochmann, 1984).

${ }^{1}$ Manuscript received 6 June 2000; revision accepted 15 February 2001.

The authors thank Organismo Autónomo de Parques Nacionales (Parque Nacional del Teide), Ministerio de Medio Ambiente for financial support; Javier Herrera, Félix Pérez Garća, Manuel Nogales, and Pedro Pérez de Paz for their comments; and Dr. Pedrola-Monfort for assistance with electrophoresis methods.

${ }^{4}$ Current address: Jardn Canario Viera y Clavijo, Apartado de correos 14, Tafira Alta. 35017 Las Palmas, Canary Islands, Spain.

${ }_{5}^{5}$ Author for reprint requests (e-mail: pedro.sosa@biologia.ulpgc.es).
The genus Cistus L. consists of 17 Mediterranean species with a mostly European distribution (Dansereau, 1939; Demoly and Montserrat, 1993; Mabberley, 1993). Five of these species occur in the Canary Islands. Cistus symphytifolius Lam., C. osbaeckiaefolius Webb ex Christ, and C. chinamadensis Bañares et Romero (Bañares and Romero, 1990) are strict endemics that were included in subg. Erythrocistus (Dun.) Willk. sect. Macrostylia Willk. by Dansereau (1939) and in subg. Cistus L. by Demoly and Montserrat (1993). The two other representatives of Cistus in the archipelago (C. monspeliensis $\mathrm{L}$. and $C$. ladanifer $\mathrm{L}$.) have a circummediterranean center of distribution and are ascribed to subg. Leucocistus Willk. (Demoly and Montserrat, 1993).

Infraspecific categories exist for both Cistus symphytifolius and C. chinamadensis based on their geographical circumscription and on morphological differences. Cistus symphytifolius var. symphytifolius is a widespread taxon in the western Canary Islands with populations in Gran Canaria, Tenerife, La Palma, and El Hierro, whereas var. leucophyllus (Spach) Dans. is confined to Gran Canaria (Kunkel, 1991). Similarly, C. chinamadensis comprises two distinct taxa: $C$. chinamadensis ssp. chinamadensis Bañares et Romero in Tenerife, and C. chinamadensis ssp. gomerae Bañares et Romero in Gomera. Both subspecies are constituted by only one population with $\sim 1000$ and 200 individuals, respectively. The species has been classified as Critical Endangered (CR B1+2c) (Bañares, Carqué, and Marrero, 1999) and is included in the Red List of Threatened Plants of the International Union for the Conservation of Nature (Walter and Gillett, 1997), as well as protected by the 


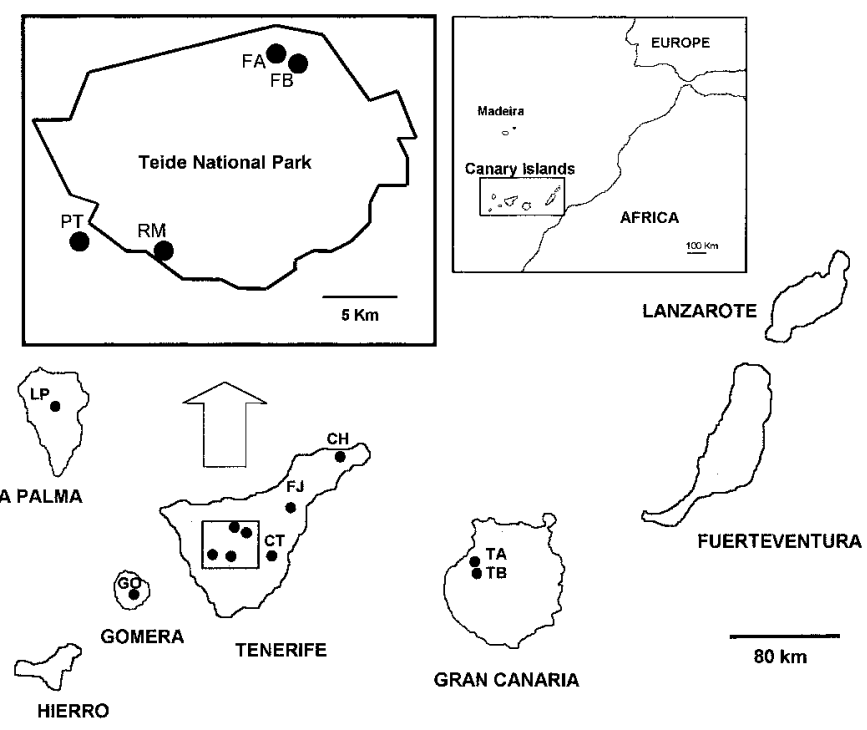

Fig. 1. Localities sampled of the three species of Canarian endemic Cistus. Population codes follow Table 1.

Canarian Government and the European Habitat Directive (Beltrán et al., 1999). Cistus symphytifolius is widely distributed and may form almost monospecific populations in the Canarian pine forests (Kunkel, 1991). Cistus osbaeckiaefolius is a local endemic with five populations in the high mountains of Tenerife, classified as Vulnerable (VU D2) (Bañares, Marrero, and Carqué, 1998; Marrero-Gómez et al., 1999).

The value of data on genetic variation for conservation of rare species has gained increasing recognition (Falk and Holsinger, 1991; Avise and Hamrick, 1996). Survival of a species in the long term depends on the maintenance of sufficient genetic variability to accommodate eventual selection pressures brought about by environmental change (Pleasants and Wendel, 1989; Richter, Soltis, and Soltis, 1994; Dolan et al., 1999). Hence, rational conservation strategies cannot be designed without estimating the amounts and apportionment of genetic variability, and this has motivated an upward surge of investigations of diversity for molecular polymorphisms in endangered species (Richter, Soltis, and Soltis, 1994; Dolan et al., 1999; Martnez-Palacios, Eguiarte, and Furnier, 1999). Al- though detailed demographic data are known to be very important in designing conservation management programs aimed at the survival of endangered taxa (Lande, 1988; Caro and Laurenson, 1994; Schemske et al., 1994), genetic studies take a primary role in planning in situ and ex situ conservation efforts (Amos and Hoelzel, 1992; Frankel, Brown, and Burdon, 1995; Gemmill et al., 1998; Francisco-Ortega et al., 2000). The Canarian Cistus have never been surveyed for molecular variation. Thereby, despite the fact that the Canarian Government fosters the preservation of these endemics, the efforts undertaken by the network of Canarian nature reserves to streamline managing programs are necessarily handicapped.

Of the many techniques presently available, perhaps enzyme electrophoresis is the most adequate as a first option. Enzyme electrophoresis provides discrete, easy-to-score, single-gene molecular markers (alleles) that are biparentally inherited and not subject to environmental plasticity. They generally adjust to a codominant pattern of expression, which is readily checked from the band intensities in heterozygous individuals.

Examples wherein allozymic variability assessments have contributed to substantiate conservation genetic efforts (Ritcher, Soltis, and Soltis, 1994; Hamrick and Godt, 1996; Gemmill et al., 1998; Dolan et al., 1999; Martinez-Palacios, Eguiarte, and Furnier, 1999; Williamson and Werth, 1999) are abundant and span a wide array of plant families.

The driving purpose of this research was to assess the genetic variability level of the three Cistus species endemic to the Canarian archipelago in the light of their levels of allozymic variation. We will use that information to suggest managing strategies for their endangered biodiversity. The study of the population variability of these endemic taxa in molecular terms has long been overdue, and this has obviously stood in the way of a proper conservation strategy. Such genetic information should help us establish conservation priorities for populations of these endangered taxa.

\section{MATERIALS AND METHODS}

Plant material-We sampled four populations of Cistus osbaeckiaefolius, two of $C$. symphytifolius var. symphytifolius, two of $C$. symphytifolius var. leucophyllus, and the single populations described for both $C$. chinamadensis ssp. chinamadensis and C. chinamadensis ssp. gomerae (Fig. 1, Table 1). Plants from a recently described population in La Palma (A. Bañares, Teide National Park) were also collected. Since thorough systematic studies of this

TABle 1. Populations examined and sampling details.

\begin{tabular}{|c|c|c|c|c|}
\hline Accession & Island & Code & Population size & Sample size \\
\hline \multicolumn{5}{|l|}{ Cistus osbaeckiaefolius } \\
\hline Fortaleza A & Tenerife & FA & 184 & 34 \\
\hline Fortaleza B & Tenerife & FB & 134 & 32 \\
\hline Roque Magdalena & Tenerife & RM & 210 & 36 \\
\hline Tágara & Tenerife & PT & $>2000$ & 62 \\
\hline \multicolumn{5}{|l|}{ C. symphytifolius var. symphytifolius } \\
\hline Fuente Joco & Tenerife & FJ & $>1000$ & 34 \\
\hline Cruz de Tea & Tenerife & CT & $>1000$ & 36 \\
\hline \multicolumn{5}{|l|}{ C. symphytifolius var. leucophyllus } \\
\hline Tamadaba A & Gran Canaria & TA & $>1000$ & 40 \\
\hline Tamadaba B & Gran Canaria & $\mathrm{TB}$ & $>1000$ & 42 \\
\hline Cistus sp. & La Palma & LP & $>1000$ & 18 \\
\hline C. chinamadensis ssp. gomerae & Gomera & GO & $\sim 200$ & 40 \\
\hline C. chinamadensis ssp. chinamadensis & Tenerife & $\mathrm{CH}$ & $\sim 1000$ & 54 \\
\hline
\end{tabular}


TABLE 2. Allele frequencies for all Cistus populations analyzed. Codes correspond to Table 1.

\begin{tabular}{|c|c|c|c|c|c|c|c|c|c|c|c|c|}
\hline \multirow[b]{2}{*}{ Locus } & \multirow[b]{2}{*}{ Allele } & \multicolumn{4}{|c|}{ C. osbaeckiaefolius } & \multirow{2}{*}{$\begin{array}{c}\text { C. sp. } \\
\text { LP }\end{array}$} & \multicolumn{2}{|c|}{ C. s. var. symphytifolius } & \multicolumn{2}{|c|}{ C. s. var. leucophyllus } & \multirow{2}{*}{$\begin{array}{c}\begin{array}{c}\text { C. c. ssp. } \\
\text { gomerae }\end{array} \\
\mathrm{GO}\end{array}$} & \multirow{2}{*}{$\frac{\begin{array}{c}\text { C. c. ssp. } \\
\text { chinamadensis }\end{array}}{\mathrm{CH}}$} \\
\hline & & FA & FB & RM & PT & & FJ & CT & TA & TB & & \\
\hline \multirow[t]{3}{*}{ Pgi-1 } & a & 0.088 & 0.750 & 1.000 & 0.375 & 0.000 & 0.000 & 0.000 & 0.000 & 0.000 & 0.000 & 0.000 \\
\hline & b & 0.912 & 0.250 & 0.000 & 0.625 & 0.888 & 0.941 & 0.767 & 0.325 & 0.300 & 1.000 & 0.000 \\
\hline & c & 0.000 & 0.000 & 0.000 & 0.000 & 0.112 & 0.059 & 0.233 & 0.675 & 0.700 & 0.000 & 1.000 \\
\hline Pgi-2 & a & 1.000 & 1.000 & 1.000 & 1.000 & 1.000 & 1.000 & 1.000 & 1.000 & 1.000 & 1.000 & 1.000 \\
\hline \multirow[t]{2}{*}{ Pgm-1 } & a & 0.000 & 0.000 & 0.278 & 0.000 & 0.167 & 0.350 & 0.036 & 0.050 & 0.048 & 0.925 & 0.000 \\
\hline & $\mathrm{b}$ & 1.000 & 1.000 & 0.722 & 1.000 & 0.833 & 0.650 & 0.964 & 0.950 & 0.952 & 0.075 & 1.000 \\
\hline \multirow[t]{3}{*}{ Pgm-2 } & a & 0.250 & 0.000 & 0.389 & 0.500 & 0.500 & 0.031 & 0.409 & 0.025 & 0.000 & 0.158 & 0.343 \\
\hline & $\mathrm{b}$ & 0.750 & 0.500 & 0.528 & 0.500 & 0.500 & 0.313 & 0.591 & 0.450 & 0.500 & 0.474 & 0.526 \\
\hline & c & 0.000 & 0.500 & 0.083 & 0.000 & 0.000 & 0.656 & 0.000 & 0.525 & 0.500 & 0.368 & 0.131 \\
\hline $6-P g d$ & $\mathrm{a}$ & 1.000 & 1.000 & 1.000 & 1.000 & 1.000 & 1.0000 & 1.000 & 1.000 & 1.0000 & 1.000 & 1.000 \\
\hline$M d h-1$ & $\mathrm{a}$ & 1.000 & 1.000 & 1.000 & 1.000 & 1.000 & 1.000 & 1.000 & 1.000 & 1.000 & 1.000 & 1.000 \\
\hline \multirow[t]{2}{*}{$M d h-2$} & a & 1.000 & 1.000 & 1.000 & 1.000 & 1.000 & 1.000 & 1.000 & 0.975 & 0.952 & 1.000 & 1.000 \\
\hline & b & 0.000 & 0.000 & 0.000 & 0.000 & 0.000 & 0.000 & 0.000 & 0.025 & 0.048 & 0.000 & 0.000 \\
\hline \multirow[t]{3}{*}{$M d h-3$} & a & 0.000 & 0.000 & 0.112 & 0.000 & 1.000 & 0.333 & 0.333 & 1.000 & 1.000 & 0.500 & 0.260 \\
\hline & b & 1.000 & 0.909 & 0.888 & 1.000 & 0.000 & 0.500 & 0.333 & 0.000 & 0.000 & 0.425 & 0.520 \\
\hline & c & 0.000 & 0.091 & 0.000 & 0.000 & 0.000 & 0.167 & 0.334 & 0.000 & 0.000 & 0.075 & 0.220 \\
\hline Est & $\mathrm{a}$ & 1.000 & 1.000 & 1.000 & 1.000 & 1.000 & 1.000 & 1.000 & 1.000 & 1.000 & 1.000 & 1.000 \\
\hline \multirow[t]{2}{*}{ Dia } & a & 0.353 & 0.334 & 0.306 & 0.000 & 0.112 & 0.265 & 0.000 & 0.275 & 0.000 & 0.050 & 0.000 \\
\hline & b & 0.647 & 0.666 & 0.694 & 1.000 & 0.888 & 0.735 & 1.000 & 0.725 & 1.000 & 0.950 & 1.000 \\
\hline \multirow[t]{2}{*}{ Idh-1 } & a & 0.000 & 0.000 & 0.000 & 0.000 & 0.000 & 0.000 & 0.000 & 0.053 & 0.188 & 0.000 & 0.000 \\
\hline & b & 1.000 & 1.000 & 1.000 & 1.000 & 1.000 & 1.000 & 1.000 & 0.947 & 0.812 & 1.000 & 1.000 \\
\hline \multirow[t]{2}{*}{$I d h-2$} & $\mathrm{a}$ & 0.000 & 0.000 & 0.000 & 0.000 & 0.000 & 0.000 & 0.000 & 0.211 & 0.125 & 0.000 & 0.000 \\
\hline & b & 1.000 & 1.000 & 1.000 & 1.000 & 1.000 & 1.000 & 1.000 & 0.789 & 0.875 & 1.000 & 1.000 \\
\hline \multirow[t]{2}{*}{$M e$} & $\mathrm{a}$ & 1.000 & 1.000 & 1.000 & 1.000 & 1.000 & 0.917 & 0.333 & 0.579 & 0.714 & 1.000 & 1.000 \\
\hline & b & 0.000 & 0.000 & 0.000 & 0.000 & 0.000 & 0.083 & 0.667 & 0.42 & 0.286 & 0.000 & 0.000 \\
\hline
\end{tabular}

new population have not yet been performed, it was included in the analyses as Cistus sp. (Fig. 1, Table 1). Given that many of these populations are endangered and occur in controlled nature reserves, we were compelled to take small samples in all cases.

Allozyme electrophoresis-About $1 \mathrm{~cm}^{2}$ of young leaves from every sampled adult individual were taken and transported in a hand cooler to our laboratory and then stored at $-80^{\circ} \mathrm{C}$. For electrophoretic assays, each sample was ground in a mortar with liquid nitrogen. After grinding, $\sim 0.5 \mathrm{~mL}$ of extraction buffer (Pedrola-Monfort and Caujapé-Castells, 1994) was added. Extracts were adsorbed onto Whatman number 1 filter papers and subjected to horizontal $14 \%$ starch gel electrophoresis for a variable time depending on the buffer system used. Three electrode/gel buffer systems allowed us to resolve eight enzyme systems: $40 \mathrm{mmol} / \mathrm{L}$ citric acid titrated to $\mathrm{pH} 6.5$ with $\mathrm{N}$ (3-aminopropyl)-morpholine/1:19 dilution of the electrode buffer was used for resolving phosphoglucoisomerase (PGI, EC 3.4.11.1), 6-phosphogluconate dehydrogenase (6-PGD, EC 1.1.1.14), malate dehydrogenase (MDH, EC 1.1.1.37), isocitrate dehydrogenase (IDH, EC 1.1.1.42), and malic enzyme (ME, EC 1.1.1.40); $0.3 \mathrm{~mol} / \mathrm{L}$ boric acid $\mathrm{pH} 8.3 / 3.6 \mathrm{mmol} / \mathrm{L}$ citric acid and $1.52 \mathrm{mmol} / \mathrm{L}$ Tris, $\mathrm{pH} 7.8$ for esterase (EST, EC 3.1.1.-) and diaforase (DIA, EC 1.6.99.-); and $0.137 \mathrm{~mol} / \mathrm{L}$ Tris and $47 \mathrm{mmol} / \mathrm{L}$ citric acid anhydrous, $\mathrm{pH}$ 7.0 / 5 mmol/L DL-histidine $\mathrm{pH} 7.0$ for phosphoglucomutase (PGM, EC 2.7.5.1). After electrophoresis, gels were sliced in different layers and specifically stained following the protocols in Wendel and Weeden (1989) and Sosa and Garcia-Reina (1993) with slight modifications. Interallele mobility was done through side-by-side comparisons of the detected allelic variants in the same gel. Interpretation of the bands assigned "a" to the allele with the fastest mobility towards the anode and a letter following the alphabetic sequence to every subsequently slower allele. The number of bands in heterozygous individuals conformed to the expected quaternary structure of the corresponding enzymes (Wendel and Weeden, 1989; Kephart, 1990), and their relative intensities were coincident with the hypothesis of Mendelian codominance.

Data analysis - The computer program BIOSYS-1 (Swofford and Selander, 1981) was used to calculate basic descriptors of allozymic variability and intra- and interspecific Nei's (1972) genetic distances. We used FSTAT (Goudet, 1995) and GENEPOP (Raymond and Rousset, 1995) to estimate and test Wright's $F$ statistics (Wright, 1965). Interpopulational number of migrants was estimated indirectly using the formula $N m=\left[\left(1 / F_{\text {ST }}\right)-1\right] /[4(n / n-1) 2]$ (Crow and Aoki, 1984), where $n$ is the number of populations. Estimators of intra- and interpopulation apportionment of allozymic variability (Nei, 1973) were calculated with Genestat-PC 3.3 (Lewis, 1993). Interpopulational relationships were estimated through the construction of a neighbor-joining cluster from pairwise Nei (1972) genetic distances in BIOSYS-1 (Swofford and Selander, 1981).

\section{RESULTS}

Genetic interpretation of the electrophoretic patterns suggests that the eight enzymes resolved were encoded by 13 putative loci (Table 2). Four of them (Pgi-2, $6 P g d$, Mdh-1, and $E s t)$ were monomorphic all over. The remaining nine loci were polymorphic either within or between populations. Loci Pgm1, Mdh-2, Dia, Idh-1, Idh-2, and Me displayed two alleles each. Three alleles were observed for Pgi-1, Pgm-2, and Mdh3. The patterns of allelic distribution and number of alleles per locus varied across populations. For most polymorphic loci, there was at least one common allele at high frequency in most populations. However, some exclusive alleles were also observed; Pgi-1a was exclusive of Cistus osbaeckiaefolius populations, whereas four alleles $(M d h-2 b, I d h-1 a, I d h-2 a$, and $M e-b)$ were detected exclusively in $C$. symphytifolius. Since none of these exclusive alleles was monomorphic, they couldn't be used for unambiguous populational ascription of individuals. No exclusive alleles were detected in $C$. chinamadensis (Table 2). At the infraspecific level, two alleles (Mdh-3b and $M d h-3 c$ ) were detected in C. symphytifolius var. symphytifolius that were absent in var. leucophyllus. Conversely, alleles $M d h-2 b, I d h-1 a$, and $I d h-2 a$ were observed in var. leucophyllus, but they were absent in var. symphytifolius. 
TABLE 3. Basic descriptors of isozymes genetic variability populations of Cistus: $p$, percentage of polymorphic loci; $A$, mean number of alleles per locus; $A_{\mathrm{p}}$, mean number of alleles per polymorphic locus; $H_{\mathrm{e}}$, expected heterozygosity; $H_{\mathrm{o}}$, observed heterozygosity.

\begin{tabular}{lccccc}
\hline \hline \multicolumn{1}{c}{ Population } & $p$ & $A$ & $A_{\mathrm{p}}$ & $H_{\mathrm{e}}$ & $H_{\mathrm{o}}$ \\
\hline Cistus osbaeckiaefolius & & & & & \\
$\quad$ Fortaleza A (FA) & 23.1 & 1.23 & 2.0 & 0.079 & 0.097 \\
$\quad$ Fortaleza B (FB) & 30.8 & 1.31 & 2.0 & 0.118 & 0.138 \\
$\quad$ Roque Magdalena (RM) & 30.8 & 1.38 & 2.0 & 0.126 & 0.128 \\
$\quad$ Tágara (PT) & 15.4 & 1.15 & 2.0 & 0.076 & 0.096 \\
Average C. osbaeckiaefolius & 25.0 & 1.27 & 2.0 & 0.099 & 0.112 \\
C. symphytifolius var. symphytifolius & & & & \\
$\quad$ Fuente Joco (FJ) & 46.2 & 1.61 & 2.3 & 0.178 & 0.105 \\
$\quad$ Cruz de Tea (CT) & 30.8 & 1.46 & 2.3 & 0.163 & 0.128 \\
C. symphytifolius var. leucophyllus & & & & \\
$\quad$ Tamadaba A (TA) & 53.8 & 1.69 & 2.1 & 0.187 & 0.223 \\
$\quad$ Tamadaba B (TB) & 38.5 & 1.54 & 2.0 & 0.161 & 0.160 \\
Average C. symphytifolius & 42.3 & 1.58 & 2.2 & 0.172 & 0.154 \\
C. chinamadensis & & & & & \\
$\quad$ ssp. gomerae (GO) & 30.8 & 1.54 & 2.5 & 0.112 & 0.100 \\
$\quad$ ssp. chinamadensis (CH) & 15.4 & 1.31 & 2.3 & 0.095 & 0.091 \\
Average C. chinamadensis & 23.1 & 1.42 & 2.4 & 0.103 & 0.095 \\
Cistus sp. (LP) & 30.8 & 1.30 & 1.8 & 0.096 & 0.102 \\
\hline
\end{tabular}

Within C. chinamadensis, ssp. gomerae and ssp. chinamadensis were monomorphic for alleles Pgi-la and Pgi-1c, respectively. Also, Pgm-la appeared at high frequency at ssp. gomerae but was absent in ssp. chinamadensis.

Genetic diversity of Cistus species-The intrapopulational estimates of genetic variability are presented in Table 3. Overall, the levels of genetic variation varied widely among populations. The mean number of alleles per locus ranged from 1.15 for Tágara population (Cistus osbaeckiaefolius) to 1.69 for Tamadaba A (C. symphytifolius var. leucophyllus). Expected heterozygosity, the more integrative measure, followed the same trend with the highest value recorded for the Tamadaba A population (C. symphytifolius var. leucophyllus) and the lowest for the Tágara population (C. osbaeckiaefolius) (Table 3).

Partitioning of genetic variation within and among populations - To analyze genetic structure within and among populations, $F$ statistics (Wright, 1965, 1978) were calculated. The partitioning of total genetic variation was very different for each taxon analyzed (Table 4). For Cistus osbaeckiaefolius and $C$. chinamadensis, $F_{\text {IT }}$ was essentially explained by a significant genetic differentiation among populations with a mean $F_{\mathrm{ST}}$ value of 0.299 and 0.614 , respectively. In contrast, most of the total genetic variation detected in C. symphytifolius var. leucophyllus was explained by the within-population component, with extremely low interpopulational genetic differentiation $\left(F_{\mathrm{ST}}=0.032\right)$. Fixation indices $\left(F_{\mathrm{IS}}\right)$ also varied widely among taxa (Tables 4 and 5). The mean $F_{\text {IS }}$ (crossed for all loci) was negative (showing excess of heterozygotes) and highly significant for $C$. osbaeckiaefolius populations. Significant deficiency of heterozygotes $\left(F_{\text {Is }}>0\right)$ was observed in both $C$. symphytifolius var. symphytifolius and $C$. chinamadensis populations. No significant deviations from Hardy-Weinberg proportions were detected for C. symphytifolius var. leucophyllus populations (Table 5).
TABLE 4. Estimates of $F$ statistics for all polymorphic loci for Cistus osbaeckiaefolius, C. symphytifolius, and C. chinamadensis.

\begin{tabular}{|c|c|c|c|}
\hline Locus & $F_{\text {IT }}$ & $F_{\text {IS }}$ & $F_{\mathrm{ST}}$ \\
\hline \multicolumn{4}{|c|}{ C. osbaeckiaefolius } \\
\hline Pgi-1 & 0.778 & 0.561 & 0.494 \\
\hline Pgm-1 & 0.803 & 0.735 & 0.257 \\
\hline Pgm-2 & -0.462 & -0.789 & 0.183 \\
\hline$M d h-3$ & 1.000 & 1.000 & 0.028 \\
\hline Dia & -0.185 & -0.476 & 0.197 \\
\hline Mean & 0.176 & -0.177 & 0.299 \\
\hline \multicolumn{4}{|c|}{ C. symphytifolius var. leucophyllus } \\
\hline Pgi-1 & 0.361 & 0.382 & -0.034 \\
\hline Pgm-1 & -0.051 & -0.026 & -0.024 \\
\hline Pgm-2 & -0.731 & -0.723 & -0.004 \\
\hline$M d h-2$ & -0.001 & -0.025 & 0.023 \\
\hline Dia & 0.007 & -0.358 & 0.268 \\
\hline Idh-1 & 0.459 & 0.433 & 0.047 \\
\hline$I d h-2$ & -0.192 & -0.194 & 0.002 \\
\hline$M e$ & 0.138 & 0.128 & 0.012 \\
\hline Mean & -0.048 & -0.083 & 0.032 \\
\hline \multicolumn{4}{|c|}{ C. symphytifolius var. symphytifolius } \\
\hline Pgi-1 & 0.878 & 0.870 & 0.064 \\
\hline Pgm-1 & 0.492 & 0.314 & 0.259 \\
\hline Pgm-2 & 0.399 & 0.027 & 0.382 \\
\hline$M d h-3$ & 0.801 & 0.818 & -0.097 \\
\hline Dia & 0.008 & -0.334 & 0.256 \\
\hline$M e$ & 0.500 & 0.054 & 0.471 \\
\hline Mean & 0.535 & 0.378 & 0.252 \\
\hline \multicolumn{4}{|c|}{ C. chinamadensis } \\
\hline Pgi-1 & 1.000 & - & 1.000 \\
\hline Pgm-1 & 0.977 & 0.652 & 0.933 \\
\hline Pgm-2 & -0.461 & -0.556 & 0.061 \\
\hline$M d h-3$ & 0.685 & 0.674 & 0.033 \\
\hline Dia & -0.017 & -0.018 & 0.001 \\
\hline Mean & 0.647 & 0.085 & 0.614 \\
\hline
\end{tabular}

Genetic relationship among taxa-The genetic distance and identity measures of Nei (1972) were calculated for all pairwise comparisons among all 11 populations (Table 6). Maximum and minimum identities $(I=0.989$ and $I=0.818)$ were found between both populations of var. leucophyllus and between Tamadaba A (var. leucophyllus) and Roque Magdalena (C. osbaeckiaefolius), respectively. The mean genetic identities treating the taxa as three different species (but disregarding Cistus sp.) were 0.883 (between $C$. chinamadensis and $C$. osbaeckiaefolius), 0.896 (between $C$. chinamadensis and $C$. symphytifolius), and 0.871 (between $C$. symphytifolius and $C$. osbaeckiaefolius). The mean genetic identities within the three species were 0.954 ( $C$. osbaeckiaefolius), 0.924 ( $C$. symphytifolius), and 0.833 (C. chinamadensis).

For all populations, the neighbor-joining tree based on Nei's genetic distance (Fig. 2) displayed two major groups. One of them was constituted by all $C$. osbaeckiaefolius populations. The other contained all populations of $C$. symphytifolius, $C$. sp., and $C$. chinamadensis (Fig. 2). The two subspecies of $C$. chinamadensis appeared separated in the tree, indicating significant divergence between them.

\section{DISCUSSION}

Cistus symphytifolius - Both varieties of this species presented high levels of genetic variation as estimated by percentage of polymorphic loci $(p)$, mean number of alleles per locus $(A)$, and expected heterozygosity $\left(H_{\mathrm{e}}\right)$. Values of these 
parameters were $p=38.5, A=1.54, H_{\mathrm{e}}=0.171$ for var. symphytifolius and $p=42.3, A=1.58, H_{\mathrm{e}}=0.172$ for var. leucophyllus. These values are very close to the average for outbreeding species with animal-mediated pollination ( $p=$ 36.0; $\left.A=1.54 ; H_{\mathrm{e}}=0.120\right)$ and slightly lower than the average for widespread species $\left(p=43.0 ; A=1.72 ; H_{\mathrm{e}}=\right.$ 0.160 ) reported by Hamrick and Godt (1989). Therefore, $C$. symphytifolius can be included in the subset of narrow endemics with high levels of genetic variability. Furthermore, its two varieties present higher genetic variation than most Canarian species analyzed by allozymes. Genetic diversity levels must be interpreted in the context of the interaction among the different factors influencing population dynamics, such as population size, mating system, mutation, gene flow, and environmental conditions (Frankel, Brown, and Burdon, 1995). Although very few studies have been made of the breeding system of the Canarian Cistus (Calero and Santos, 1988; Pérez-Garća, 1995), numerous works with their mainland relatives show that most of Cistus species are self-incompatible (Bosch, 1992; Herrera, 1992; Talavera, Gibbs, and Herrera, 1993; J. Herrera, University of Seville, personal communication; F. Pérez-Garća, Polytechnic University of Madrid, personal communication). High levels of within-population genetic variation, together with the inconspicuous genetic differentiation among populations $\left(F_{\mathrm{ST}}=0.032\right)$ and the lack of deviation from Hardy-Weinberg proportions in $C$. symphytifolius var. leucophyllus, suggest that it is an outcrossing species and that its populations might have experienced gene flow in recent times or diverged relatively shortly ago. In addition, these results indicate that populations of var. leucophyllus are not substantially structured genetically.

In contrast, $C$. symphytifolius var. symphytifolius exhibits highly significant heterozygote deficiency at most loci $\left(F_{\text {IS }}>\right.$ 0 ; Table 5). This result cannot be explained by chance alone or by intensive inbreeding, because in this case we would expect heterozygote deficiencies at all loci. Rather, it suggests that var. symphytifolius populations may be genetically structured (i.e., composed of subpopulations within which mating is approximately random but between which mating may be infrequent). Such structuring of genetic variability is a frequently reported feature of insect-pollinated herbs (Heywood, 1991; Westerbergh and Saura, 1994; McCauley et al., 1996; Williamson and Werth, 1999), and most rare species also do exhibit large discrepancies between mean observed and expected heterozygosity values (Ellstrand and Ellam, 1993). Thus, var. symphytifolius is probably an outbreeder, and the genetic structuring found in the populations might be caused by sampling bias. The sampling area of var. symphytifolius populations was considerably wider than that for var. leucophyllus. Under this scenario, the observed deficiency of heterozygotes could be due to the Wahlund effect (Hartl and Clark, 1997).

Further, Cistus symphytifolius var. symphytifolius appears to have genetic structure at a large spatial scale, as indicated by the average among-population $F_{\mathrm{ST}}$ value of 0.252 (Table 4). Wright (1965) suggested that $F_{\mathrm{ST}}$ values above 0.20 reflect low rates of gene flow among populations. On this basis, little gene flow seems to be the rule between populations of var. symphytifolius, since $F_{\mathrm{ST}}$ values were higher than 0.25 (Table 4) in four out of six loci. Estimation of the number of migrants per generation supports this scenario because its value $\left(N_{\mathrm{m}}=\right.$ 0.66) is below the theoretical threshold of one migrant per generation assumed to prevent independent population evolu- 
TABLE 6. Values of genetic distances (below dashes) and identities (above dashes) (Nei, 1972) among populations.

\begin{tabular}{|c|c|c|c|c|c|c|c|c|c|c|c|}
\hline & \multirow{2}{*}{\multicolumn{4}{|c|}{ Cistus osbaeckiaefolius }} & \multirow{3}{*}{$\frac{\text { Cistus sp. }}{\text { LP }}$} & \multicolumn{4}{|c|}{ Cistus symphytifolius } & \multicolumn{2}{|c|}{ Cistus chinamadensis } \\
\hline & & & & & & \multicolumn{2}{|c|}{ var. symphytifolius } & \multicolumn{2}{|c|}{ var. leucophyllus } & ssp. gomerae & \multirow{2}{*}{$\begin{array}{c}\begin{array}{c}\text { ssp. chinama } \\
\text { densis }\end{array} \\
\mathrm{CH}\end{array}$} \\
\hline & FA & FB & RM & PT & & FJ & $\mathrm{CT}$ & TA & TB & $\mathrm{GO}$ & \\
\hline FA & - & 0.946 & 0.918 & 0.978 & 0.903 & 0.942 & 0.916 & 0.839 & 0.837 & 0.885 & 0.895 \\
\hline FB & 0.055 & - & 0.973 & 0.957 & 0.851 & 0.926 & 0.870 & 0.851 & 0.850 & 0.847 & 0.900 \\
\hline RM & 0.085 & 0.028 & - & 0.951 & 0.849 & 0.881 & 0.852 & 0.818 & 0.819 & 0.849 & 0.890 \\
\hline PT & 0.023 & 0.044 & 0.051 & - & 0.904 & 0.926 & 0.923 & 0.834 & 0.848 & 0.880 & 0.919 \\
\hline LP & 0.102 & 0.161 & 0.163 & 0.101 & - & 0.933 & 0.928 & 0.927 & 0.934 & 0.920 & 0.891 \\
\hline FJ & 0.059 & 0.077 & 0.126 & 0.077 & 0.070 & - & 0.918 & 0.906 & 0.903 & 0.959 & 0.886 \\
\hline $\mathrm{CT}$ & 0.087 & 0.139 & 0.160 & 0.080 & 0.075 & 0.085 & - & 0.914 & 0.912 & 0.872 & 0.906 \\
\hline TA & 0.176 & 0.162 & 0.201 & 0.181 & 0.076 & 0.099 & 0.090 & - & 0.989 & 0.845 & 0.915 \\
\hline TB & 0.178 & 0.163 & 0.199 & 0.165 & 0.068 & 0.102 & 0.092 & 0.011 & - & 0.855 & 0.931 \\
\hline GO & 0.122 & 0.166 & 0.164 & 0.128 & 0.083 & 0.042 & 0.137 & 0.169 & 0.156 & - & 0.833 \\
\hline $\mathrm{CH}$ & 0.111 & 0.106 & 0.116 & 0.084 & 0.115 & 0.121 & 0.098 & 0.089 & 0.071 & 0.182 & - \\
\hline
\end{tabular}

tion (Slatkin, 1985, 1987, 1994). Although this result is unexpected on the grounds of their geographical proximity (roughly within $30 \mathrm{~km}$ ), we must bear in mind that these populations are separated by deep ravines and cliffs and display slightly different ecological preferences, which could explain the genetic differentiation observed.

Sharp genetic differentiation has been also described in other endemic Canarian species. The average $G_{\mathrm{ST}}$ value (multiple allele extension of Wright's $F_{\mathrm{ST}}$; Nei, 1973) in a survey of 17 Canarian species (Francisco-Ortega et al., 2000) was 0.338, which is comparable to the value calculated for 30 species from the Juan Fernández Islands in the same survey. Kim et al. (1999) detected similar values of genetic differentiation $\left(G_{\mathrm{ST}}=0.271\right)$ in two populations of Prenantes pendula from Gran Canaria separated $<5 \mathrm{~km}$. Even higher values were observed between populations of Babcockia platylepis $\left(G_{\mathrm{ST}}=\right.$ $0.538)$, Sonchus brachylobus $\left(G_{\mathrm{ST}}=0.535\right)$, S. gonzalezpadroni $\left(G_{\mathrm{ST}}=0.294\right)$, S. palmensis $\left(G_{\mathrm{ST}}=0.401\right)$, or S. pinnatifidus $\left(G_{\mathrm{ST}}=0.392\right)$, all of which were localized at the same island $<50 \mathrm{~km}$ apart from each other. As discussed by Francisco-Ortega et al. (2000), high genetic differentiation values in Canarian endemics indicate that there must have been
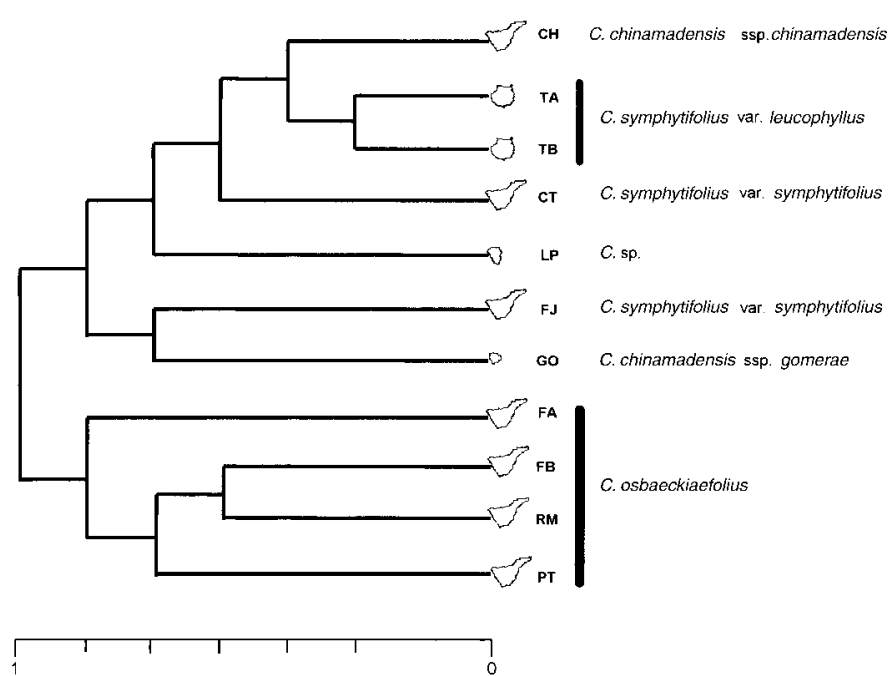

Fig. 2. Neighbor-joining cluster based on Nei's (1972) genetic distances among the populations examined. Geographical distribution of the stands is given by the shape of the island at the tips of the branches. Population codes follow Table 1 . low levels of gene flow among populations despite their being predominantly outcrossing. However, it is worth noting that making direct comparisons among Canarian taxa may be hindered by differences in population and sample sizes, breeding systems, morphological and ecological factors, and the particular loci surveyed. In particular, Hamrick and Godt's (1989, 1997) reviews emphasize that geographic range explains little of the interpopulation genetic differentiation. Endemic and narrowly distributed species have $G_{\mathrm{ST}}$ values that are equivalent or smaller than those of more widely distributed species (Hamrick and Godt, 1989, 1997).

As is the case in other Cistus species (Corral, Pita, and Pérez-Garća, 1990), population dynamics of the two varieties of $C$. symphytifolius are relatively stable, with long individual life spans and resprouting following fire (Trabaud and Oustric, 1989; P. Pérez de Paz, University of La Laguna, personal communication). Both varieties grow extensively in Canarian pine forests that have undergone several episodes of burning through their history. The variety symphytifolius is the dominant form in the Canaries and occurs over large areas in pine forests (Kunkel, 1991; Rivas-Martnez et al., 1993). Although var. leucophyllus is restricted to Gran Canaria, its levels of genetic variation coincide with those reported for other oceanic island endemics (Witter and Carr, 1988; Westerbergh and Saura, 1994; Kim et al., 1999; Francisco-Ortega et al., 2000). Taking into account that Gran Canaria is the oldest island where Cistus occurs, it is feasible that var. leucophyllus established earlier in Gran Canaria than var. symphytifolius in Tenerife, and, therefore, it must have had more time to accumulate mutations and build up genetic variability.

Cistus chinamadensis-Cistus chinamadensis populations maintain intermediate values for most genetic variability parameters $\left(p=23.1 ; A=1.42 ; H_{\mathrm{e}}=0.103\right)$. At odds with expectations based on its narrow geographical range (a single population for either of its two varieties) and the very small population sizes, these values rank higher than the averages reported for either inbreeding species or endemics (Hamrick and Godt, 1989). Remarkably, ssp. gomerae, where the negative impact of genetic drift on levels of genetic diversity should be more dramatic due to its small size $(<200$ individuals), presents more genetic variability than ssp. chinamadensis (with nearly fivefold more individuals). Values of $F_{\text {IS }}$ indicate significant heterozygote deficiency for both populations (Table 5). As is the case for other Canarian Cistus, no data on 
reproductive biology are available in the literature for this species. Although we cannot evaluate the extent of inbreeding in these populations, the relatively high levels of genetic variation detected seem to rule it out as a common reproductive feature, a result that is compatible with self-incompatibility reported for most of their mainland congeners. It is plausible that outbreeding in combination with relatively high intrapopulational gene flow counterbalanced the effect of genetic drift in this taxon.

High genetic differentiation between the two $C$. chinamadensis populations (as estimated from $F_{\mathrm{ST}}$ and genetic identity) is unexpected in the light of the generally accepted view of low allozymic differentiation coupled with considerable morphological differences in island endemics (Hellenurm and Ganders, 1985; Crawford, Whitkus, and Stuessy, 1987; Witter and Carr, 1988). However, it is very important to consider that these populations are localized in different islands (Tenerife and Gomera) and consequently geographically isolated, which could explain the high $F_{\mathrm{ST}}$ value $(0.614)$ and the relatively low genetic identity $(I=0.833)$ between them. Also, patchy distribution and environmental factors may have contributed over historical times to increase genetic differentiation between stands.

Cistus osbaeckiaefolius-Cistus osbaeckiaefolius has the lowest genetic variation levels of the three species studied (Table 3), though they are still within the range described for endemic plants by Hamrick and Godt (1989). Only five extant populations of this strict endemic to Tenerife are known. All of them except for Tágara are localized at high mountain habitats with census sizes of $<200$ individuals per population (Marrero-Gómez et al., 1999). High $F_{\mathrm{ST}}$ values detected in this species (mean $F_{\mathrm{ST}}=0.299$ ) suggest surprisingly little interpopulation genetic exchange despite the geographic proximity. While directing attention to the possibility of a low pollination effectiveness, this conspicuous genetic differentiation could also be due to high levels of genetic drift, with mutations occurring over a long period since the populations were separated and/or local selection is acting on the allozyme loci.

Populations occurring in high mountain habitats (Fortaleza A, Fortaleza B, and Roque Magdalena) have been exposed to intensive grazing, mainly by goats and rabbits, for the last 900 yr (Bañares, Castroviejo, and Real, 1993; Marrero-Gómez et al., 1999). This factor makes it feasible that they underwent qualitatively different, recent bottlenecks. Concomitantly, the effects of human activities may have caused severe fragmentation of these populations, thus increasing the differentiation among them due both to substantial losses of diversity and to a differential action of genetic drift. Further evidence that these populations might have gone through bottlenecks is that they present the lowest average number of alleles per locus (Table 3 ). Loss of alleles rather than reduction in heterozygosity is the primary result following the severe population size reductions implicit in a bottleneck (Templeton, 1980; Sytsma and Schaal, 1985).

We hypothesize that habitat fragmentation and the loss of individuals and/or populations have increased genetic differentiation among $C$. osbaeckiaefolius populations on a small geographical scale. Estimates of $N_{\mathrm{m}}$ over all populations vary and range between 0.392 and 1.52 . On the whole, they are lower than the threshold of the one migrant per generation that is considered necessary to prevent independent population evolution (Slatkin, 1985, 1987, 1994; Martnez-Palacios,
Eguiarte, and Furnier, 1999). Consequently, these populations might fit a situation in which drift would override the effects of gene flow (Slatkin, 1987). In the face of the patchy distribution of the populations, their small sizes, narrow geographical occurrence, and the general predominance of outcrossing systems in Cistus (Brandt and Gottsberger, 1988; Herrera, 1992; Calero and Santos, 1993), high interpopulation differentiation in $C$. osbaeckiaefolius is best explained by genetic drift operating on an already impoverished allelic diversity.

Demographic fluctuations associated with bottlenecks or even local extirpations in these high mountain ecosystems might have also influenced the high $F_{\mathrm{ST}}$ values in this taxon (Milligan, Leebens-Mack, and Strand, 1994). This hypothesis is supported by allozyme data that display higher values of overall genetic diversity estimators in Fortaleza B than in Fortaleza A. However, we cannot discard the eventual action of natural selection in the extreme high mountain environment to explain the speciose pattern observed in this taxon. Indeed, the excess of heterozygotes $\left(F_{\mathrm{IS}}<0\right)$ detected in all $C$. osbaeckiaefolius populations (Table 5) may be either the result of random stochastic events or the consequence of balancing selection promoting high heterozygosity. In any case, it is highly improbable that all populations have an excess of heterozygotes by chance alone.

The fact that the Tágara population presented the lowest genetic variability of all Cistus populations analyzed (Table 3) is unexpected for two reasons: first, because this result is inconsistent with its relatively large size (several thousand individuals), and second, because this population extends over $\sim 15$ ha in a forest of Pinus canariensis, which constitutes a more homogeneous environment than high mountain habitats. At this point, it is also important to emphasize that the size structures and the height distributions differed significantly in the Tágara population (Marrero-Gómez et al., 1999), which could help explain the genetic results.

Interspecific relationships-A number of electrophoretic studies suggest that the levels of allozyme divergence often reported for congeneric species on oceanic islands probably result from the combined effects of genetic bottlenecks associated with colonization, small population sizes, and recent speciation on the younger islands (Lowrey and Crawford, 1985; Crawford, Whitkus, and Stuessy, 1987; Witter and Carr, 1988; Garnatje, Susanna, and Messeguer, 1998).

The levels of variability detected in Cistus allow us to substantiate a discussion of their genetic relationships. Fourteen of the 25 alleles were common to all taxa analyzed, and this furnishes proof of their shared evolutionary history. A close relatedness between two Brighamia species from Hawaii was inferred from their sharing of only six alleles out of 22 (Gemmill et al., 1998). In their work with the silversword alliance in the Hawaiian Islands, Witter and Carr (1988) presented compelling evidence that the action of mutation had been most important in the divergence observed at allozyme loci. Similar conclusions have been reached for Canarian species (Francisco-Ortega et al., 2000). Therefore, time since origin must have been a most important factor for the allozymic divergence observed among and within islands. Assuming that divergence among these species of Cistus is due exclusively to mutation and drift, overall levels of variability can give us an indication of which of these three species might have been the first to establish in the Canaries. Cistus symphytifolius presents a higher number of exclusive alleles (Table 2). This, together 
with the fact that it was by far the species with higher values of genetic variability and observed heterozygosity (Table 3), singles it out as the one that must have had more time to diverge. Unfortunately, we cannot evaluate the contribution of events in evolutionary history relative to ecological time to the genetic diversity of these species because of the absence of continental relatives in our allozymic analysis.

The relatively high genetic identity between $C$. osbaeckiaefolius and $C$. symphytifolius $(I=0.871)$, the reduced genetic variability in $C$. osbaeckiaefolius populations, and the presence of nearly all of the alleles of $C$. symphytifolius in $C$. osbaeckiaefolius populations support the view that $C$. osbaeckiaefolius arose via a founder event from $C$. symphytifolius or a very close relative. Similar examples in the literature indicate that endemic species often have considerably less variation than the more widespread congeners from which they may have been derived (Lowrey and Crawford, 1985; Witter and Carr, 1988; Pleasants and Wendel, 1989; however, see also Gemmill et al., 1998).

Quite a different picture emerges for the recently described C. chinamadensis. Although neither population of this taxon shows exclusive alleles, both are monomorphic for different alleles at the Pgi-1 locus and diverge conspicuously in terms of allele frequencies at the Pgm-1 locus. Based on the detected amounts of allozymic variability, the hypothesis that the two stands of $C$. chinamadensis did not originate from one another but instead via qualitatively different foundations from C. symphytifolius (or a close continental relative) is the best supported. Qualitative evidence of such a relationship is given by the sharing of Pgi-1c between $C$. chinamadensis ssp. chinamadensis and all populations ascribed to $C$. symphytifolius. Remarkably, this allele was not detected in C. osbaeckiaefolius. Furthermore, the remaining alleles that were detected in C. chinamadensis are at much higher frequencies in C. symphytifolius than in $C$. osbaeckiaefolius. The neighbor-joining cluster (Fig. 2) provides quantitative support for this relationship. The two $C$. chinamadensis populations are sharply separated from each other within the cluster corresponding to $C$. symphytifolius. According to this representation, C. chinamadensis ssp. chinamadensis is much closer to C. symphytifolius var. leucophyllus populations from Gran Canaria than to $C$. chinamadensis ssp. gomerae, which clusters with $C$. symphytifolius var. symphytifolius population from Tenerife. Geological evidence agrees with this result by indicating that the region called Anaga (where $C$. chinamadensis ssp. chinamadensis occurs) was the first part of Tenerife to emerge from the ocean (Schmincke, 1976). Since the island of Gran Canaria is geologically older than Tenerife (Carracedo, 1984, 1994; Garcia-Talavera, 1999) and geographically closer to Anaga, it is feasible that a founder event from a population of $C$. symphytifolius var. leucophyllus (or a very close relative) produced $C$. chinamadensis ssp. chinamadensis in Tenerife. A close morphological link between $C$. chinamadensis and C. symphytifolius var. leucophyllus was established by Bañares and Romero (1990) when they described the former species. Interpretation of the cluster in Fig. 2 and of the sharing of alleles between pairs of species in terms of these data suggests that the origin of $C$. chinamadensis ssp. gomerae from La Gomera might have been $C$. symphytifolius var. symphytifolius from Tenerife or a very close relative. This is counterintuitive, because Gomera Island, with $\sim 12$ my, is older than the Anaga region in Tenerife whose estimated age is $8.0 \mathrm{my}$. Although a founding event from Gran Canaria is also conceivable, it seems less likely on biogeographical grounds.

It bears mentioning that Nei's genetic distance (Table 6) between the two $C$. chinamadensis stands $(D=0.182)$ is substantially higher than that between $C$. symphytifolius and $C$. osbaeckiaefolius $(D=0.135)$ and more than twofold the average between populations of $C$. symphytifolius $(D=0.077)$. Other authors working with Canarian taxa explain sharp intraspecific divergence at isozyme loci similarly. Francisco-Ortega et al. (1996) and Garnatje, Susanna, and Messeguer (1998) argue for Argyranthemum and Cheirolophus, respectively, that due to a recent divergence-as morphological similarity also suggests in Cistus - the founding of new populations has been driven by successive genetic bottlenecks followed by the sorting of ancestral allozyme polymorphisms. The gradual divergence in response to a geographic splitting by dispersal or vicariance events and to ecological conditions that has been hypothesized in Cistus might have combined with the action of stochastic forces to increase the genetic differentiation observed in both $C$. chinamadensis stands.

Finally, allozyme data suggest that the stand from La Palma designated as Cistus sp. could belong to the group of C. symphytifolius because this population presents all the alleles detected in C. symphytifolius (Table 2) and is within the same cluster in the phenogram (Fig. 2). However, a review of the Canarian circumscription of Cistus would be necessary before reaching any conclusions about the taxonomic status of this population.

Conservation implications - Thus far, we have only interpreted the detected amounts of genetic variability in terms of their evolutionary implications. However, once our operative biological units have been circumscribed, the levels and distribution of allozymic variation in these endemic Cistus have a clear ramification to suggest appropriate management strategies for their endangered variability, especially for C. osbaeckiaefolius and $C$. chinamadensis.

Knowledge of the levels and distribution of genetic diversity of threatened and endangered species has been thus far an important element in designing conservation programs (Hamrick, 1983; Chamberlain, 1998; Francisco-Ortega et al., 2000). The assumption underlying the use of allozymes in conservation studies is that the levels of variation detected could be in direct relation to fitness (Milligan, Leebens-Mack, and Strand, 1994; David, 1998). Thus, knowledge of genetic variation within a taxon is crucial because of its implications for the long-term survival and continued evolution of a population or species (Frankel, Brown, and Burdon, 1995; Avise and Hamrick, 1996).

For $C$. chinamadensis only two populations are known, and therefore both of them should be preserved. In addition, our data show that the two subspecies of $C$. chinamadensis, although morphologically and ecologically similar, are genetically distinct. Thus, from a genetic conservation perspective, both of them should be given special attention when considering the preservation of the species' variability. Because little gene flow (if at all) seems to exist between $C$. chinamadensis populations as indicated by high $F_{\mathrm{ST}}$ values, artificial gene flow through transplantations should be avoided. This would entail some risks, given that it might trigger changes in the genetic composition of the populations leading to a decreased fitness through outbreeding depression and disruption of locally adapted gene combinations (Leberg, 1993; Storfer, 1999). In- 
deed, demographic studies and a monitoring program of $C$. chinamadensis ssp. gomerae promoted by Garajonay National Park for conservation purposes have always involved individuals from the same populations.

Cistus osbaeckiaefolius populations are being monitored under Teide's National Park "Recovery Plan for the Threatened Flora' (Bañares, Castroviejo, and Real, 1993; Bañares, Carqué, and Marrero, 1995). Nowadays, demographic studies reveal that all populations are stable with a constant recruitment rate (Marrero-Gómez et al., 1999), and one could expect that they would remain so in the absence of unexpected threatening factors. However, they maintain low levels of genetic variability deriving from habitat fragmentation and bottlenecks, which have led to genetic polymorphism erosion and loss of allelic richness. In the long term, this may compromise their ability to respond to changing selection pressures. The high level of differentiation among populations of C. osbaeckiaefolius represents a real conservation challenge. We can theoretically conserve almost $99 \%$ of the total allozyme diversity in the species preserving just two populations. RM and FB populations harbor all rare alleles detected by electrophoresis in C. osbaeckiaefolius such as Pgm-1a, Mdh-3a, and $P g m-2 c$. Although the electrophoretically detected alleles probably do not confer adaptation, an attempt should also be made to preserve populations that contain rare alleles. The preservation of these alleles and those linked to them may ultimately affect the long-term survival of this species. Also, at the ex situ level, sampling intensively in these both populations would fulfill the objective of capturing most of the detected genetic variability. Also, RM and FB populations contain high levels of heterozygosity (Table 3) and therefore are also clearly important from a purely conservationist perspective.

Before making any management decisions on the basis of allozyme data, however, one should recognize that populations that appear to be uniform or very similar allozymically may actually have special adaptations to their specific environments and may contain genetic variation for morphological and physiological characters that will not be apparent through starchgel electrophoresis of a limited number of allozymes.

Therefore, conservation decisions should of course include many additional scientific considerations, and although allozyme loci may provide one starting point, other factors must be considered as well. As stated by Bañares, Carqué, and Marrero (1995), the main objective of a recovery plan is the preservation of genetic diversity, especially by the perpetuation of species in their natural habitat without any specific human aid. Although genetic evidence suggests that the Tágara population is genetically depauperated, it is plausible that this population (the only one of $C$. osbaeckiaefolius growing in pine forests) possesses adaptive traits different from those associated with conspecific populations localized at high mountain habitats. It seems thus advisable to give to Tágara population a conservation priority on ecological grounds.

Our survey of allozyme markers in the three species of Cistus endemic to the Canary Islands has allowed us to substantiate a discussion bearing on their genetic relations and to give directions for the conservation of their threatened variability. These results also indicate two main lines of action for future research. One of them is to enhance the present sampling to include the other two Cistus species occurring in the Canary Islands and a consistent representation of their mainland relatives. This would facilitate establishing the probable sequence of founding events that gave rise to these island species and clarifying whether the levels of variability of the Canarian Cistus are depauperated relative to their continental congeners. Furthermore, in the face of the probable bias resulting from the low levels of variability detected, our assessment should benefit from comparison with evidence from other sources of molecular and biological information. Studies of endangered species suggest the use of more than one class of molecular markers (Chase, Kesseli, and Bawa, 1996). Future molecular biology analyses combined with ongoing reproductive biology studies are expected to provide valuable additional data to augment the present conclusions.

\section{LITERATURE CITED}

Amos, B., AND A. R. HoElzel. 1992. Applications of molecular genetic techniques to the conservation of small populations. Biological Conservation 61: 133-144.

Avise, J. C., AND J. L. HAMrick. 1996. Conservation genetics, case histories from nature. Chapman and Hall, New York, New York, USA

Ayensu, E. S. 1983. The world's diminishing plant resources. In S. K. Jain and K. L. Mehra [eds.], Conservation of tropical plant resources. Proceeding of the regional workshop on conservation of tropical plant resources in South-east Asia, 19-28. Howrah, India, Botanical Survey of India, Department of Environment, Government of India, New Delhi, India.

Bañares, A., AND P. Romero. 1990. Cistus chinamadensis, sp. nov. (Cistaceae) nuevo endemismo Canario. Studia Botanica 9: 119-128.

Bañares, A., E. Carqué, And M. Marrero. 1995. The implementation of recovery plans in the Canary Islands National Parks: methods and criteria. In J. Newton [ed.], Planta Europa. Proceedings of the first European conference on the conservation of wild plants, 145-149. Plantlife, London, UK.

Bañares, A., E. Carqué, And M. Marrero. 1999. Cistus chinamadensis Bañares et Romero. In E. Beltrán, W. Wildpret, M. C. León, A. García, and J. Reyes [eds.], Libro Rojo de la Flora Canaria contenida en la Directiva-Hábitats Europea. Organismo Autónomo de Parques Nacionales, Madrid, Spain.

Bañares, A., M. CASTRoviejo, And J. Real. 1993. Recovery plan for the threatened flora of the Teide National Park I. Cistus osbaeckiaefolius Webb ex Christ and Helianthemum juliae Wildprett. Boletim do Museo Municipal do Funchal Sup1.2: 41-56.

Bañares, A., M. Marrero, And E. Carqué. 1998. The application of the revised IUCN Red List Categories to the National Parks Flora of the Canary Islands. In H. Synge and J. Akeroyd [eds.], Planta Europa. Proceedings of the second European conference on the conservation of wild plants, 172-178. Plantlife and The Swedish Threatened Species Unit, Upssala, Sweden.

Beltrán, E., W. Wildpret, M. C. León, A. García, and J. Reyes. 1999. Libro Rojo de la Flora Canaria contenida en la Directiva Hábitats Europea. Organismo Autónomo de Parques Nacionales, Madrid, Spain.

Bosch, J. 1992. Floral biology and pollinators of three co-ocurring Cistus species (Cistaceae). Botanical Journal of the Linnean Society 109: 3955.

Bramwell, D. 1990. Conserving biodiversity in the Canary Islands. Annals of the Missouri Botanical Garden 77: 28-37.

BRANDT, U., AND G. GoTTSBERGER. 1988. Flower phenology, pollinating insects and breeding systems in Cistus, Halimium, and Tuberaria species in Portugal. Lagascalia 15 (supplement): 625-634.

Brochmann, C. 1984. Hybridization and distribution of Argyranthemum coronopifolium (Asteraceae: Anthemideae) in the Canary Islands. Nordic Journal of Botany 4: 729-736.

CAlero, A., AND A. SAntos. 1993. Reproductive biology of the high altitude Canarian flora. In H. Demiritz and Ozhatay [eds.], Proceedings of the Fifth Optima meeting, 8-15 September 1986, 497-502. University of Istanbul, Istanbul, Turkey.

Calero, A., And A. SAntos. 1988. Bioloǵa reproductiva de especies amenazadas en la flora Canaria. Lagascalia 15 (supplement): 661-664.

CARo, T. M., AND M. K. LAurenson. 1994. Ecological and genetic factors in conservation: a cautionary tale. Science 263: 485-486.

Carracedo, J. C. 1984. Marco geográfico. In L. Afonso [ed.], Geografía de 
Canarias. Geografía física, vol. 1, 9-16. Interinsular Canaria, Santa Cruz de Tenerife, Canary Islands, Spain.

CARRACEDO, J. C. 1994. The Canary Islands: an example of structural control on the growth of large oceanic islands volcanoes. Journal of Volcanology and Geothermal Research 60: 225-241.

Chamberlain, J. R. 1998. Isozyme variation in Calliandra calothyrsus (Leguminosae): its implications for species delimitation and conservation. American Journal of Botany 85: 37-47.

Chase, M., R. Kesseli, And K. Bawa. 1996. Microsatellite markers for population and conservation genetics of tropical trees. American Journal of Botany 83: 51-57.

Corral, R., J. M. Pita, and F. Pérez-García. 1990. Some aspects of seed germination in four species of Cistus L. Seed Science and Technology 18: 321-325.

Crawford, D. J., R. Whitkus, ANd T. F. Stuessy. 1987. Plant evolution and speciation on oceanic islands. In K. Urbanska [ed.], Patterns of differentiation in higher plants, 183-199. Academic Press, London, UK.

CROW, J. F., AND K. AOKI. 1984. Group selection for a polygenic behavioral trait: estimating the degree of population subdivision. Proceedings of the National Academy of Sciences, USA 81: 6073-6077.

Dansereau, P. 1939. Monographie du genre Cistus L. Boissiera 4: 1-90.

DAVID, P. 1998. Heterozygosity-fitness correlations: new perspectives on old problems. Heredity 80: 531-537.

Demoly, J.-P., And P. MontserRat. 1993. Cistus. In M. Castroviejo et al. [eds.], Flora Ibérica: plantas vasculares de la Peńnsula Ibérica e Islas Baleares, vol. 3, 319-337. Real Jardn Botánico de Madrid, Centro Superior de Investigaciones Cienfficas, Madrid, Spain.

Dolan, J., R. Yahr, E. S. Menges, and M. D. Halfhill. 1999. Conservation implications of genetic variation in three rare species endemic to Florida Rosemary Scrub. American Journal of Botany 86: 1556-1562.

Ellstrand, N. C., AND D. R. Ellam. 1993. Population genetic consequences of small population size: implications for plant conservation. Annиal Review of Ecology and Systematics 24: 217-242.

FALK, D. A., AND K. E. Holsinger. 1991. Genetics and conservation of rare plants. Oxford University Press, Oxford, UK.

Francisco-Ortega, J., D. J. Crawford, A. Santos-Guerra, and J. A. CarvalHo. 1996. Isozyme differentiation in the endemic genus Argyranthemum (Asteraceae: Anthemideae) in the Macaronesian Islands. Plant Systematics and Evolution 202: 137-152.

Francisco-Ortega, J., A. Santos-Guerra, S.-C. Kim, and D. J. CrawFORD. 2000. Plant genetic diversity in the Canary Islands: a conservation perspective. American Journal of Botany 87: 909-919.

Frankel, O. H., A. H. D. Brown, ANd J. J. Burdon. 1995. The conservation of plant biodiversity. Cambridge University Press, Cambridge, UK.

García-Talavera, F. 1999. La Macaronesia. Consideraciones geológicas, biogegráficas y paleoecológicas. In J. M. Fernández-Palacios, J. J. Bacallado, and J. A. Belmonte [eds.], Ecoloǵa y cultura en Canarias, 3964. Museo de la Ciencia, Cabildo Insular de Tenerife, Santa Cruz de Tenerife, Canary Islands, Spain.

Garnatje, T., A. Susanna, AND R. Messeguer. 1998. Isozyme studies in the genus Cheirolophus (Asteraceae: Cardueae-Centaureinae) in the Iberian Peninsula, North Africa and the Canary Islands. Plant Systematics and Evolution 213: 57-70.

Gemmill, C. E. C., T. A. Ranker, D. Ragone, S. P. Perlman, and K. R. WooD. 1998. Conservation genetics of the endangered endemic Hawaiian genus Brighamia (Campanulaceae). American Journal of Botany 85: 528-539.

GOUDET, J. 1995. FSTAT, version 1.2: a computer program to calculate Fstatistics. Journal of Heredity 86: 485-486.

HAMRICK, J. L. 1983. The distribution of genetic variation within and among natural plant populations. In C. M. Schonewald-Cox, S. M. Chambers, B. McBryde, and W. L. Thomas [eds.], Genetics and conservation, 335348. Benjamin/Cummings, Menlo Park, California, USA.

Hamrick, J. L., AND M. J. W. GodT. 1989. Allozyme diversity in plant species. In H. D. Brown, M. T. Clegg, A. L. Kahler, and B. S. Weir [eds.], Plant population genetics, breeding, and genetic resources, 43-63. Sinauer, Sunderland, Massachusetts, USA.

HAMrick, J. L., AND M. J. W. GodT. 1996. Conservation genetics of endemic plant species. In J. C. Avise and J. L. Hamrick [eds.], Conservation genetics: case studies from nature, 281-301. Chapman and Hall, New York, New York, USA.

Hamrick, J. L., AND M. J. W. GodT. 1997. Effects of life history traits on genetic diversity in plant species. In J. Silverstown, M. Franco, and J. L. Harper [eds.], Plant life histories: ecology, phylogeny and evolution, 102-118. The Royal Society, Cambridge University Press, Cambridge, UK.

Hartl, D. L., AND A. G. Clark. 1997. Principles of population genetics. Sinauer, Sunderland, Massachusetts, USA.

Helenurm, K., AND F. R. GANDERs. 1985. Adaptive radiation and genetic differentiation in Hawaiian Bidens. Evolution 39: 753-765.

Herrera, J. 1992. Flower variation and breeding system in the Cistaceae. Plant Systematics and Evolution 179: 245-255.

HeYwood, J. S. 1991. Spatial analysis of genetic variation in plant populations. Annual Review of Ecology and Systematics 22: 335-355.

KePHART, S. R. 1990. Starch gel electrophoresis of plant isozymes: a comparative analysis of techniques. American Journal of Botany 77: 693712.

Kim, S.-G., D. J. Crawford, J. Francisco-Ortega, and A. SANTOS-GuerRA. 1999. Adaptive radiation and genetic differentiation in the woody Sonchus alliance (Asteraceae: Sonchiae) in the Canary Islands. Plant Systematics and Evolution 215: 101-118.

KunKel, G. 1991. Flora y vegetación del archipiélago Canario. Tratado flor'stico, vol. 2, Dicotiledóneas. Edirca, Las Palmas de Gran Canaria, Canary Islands, Spain.

LANDE, R. 1988. Genetics and demography in biological conservation. Science 241: $1455-1460$

LEBERG, P. L. 1993. Strategies for population reintroduction: effects of genetic variability on population growth and size. Conservation Biology 7: 194-199.

LEwIS, P. O. 1993. Genestat-pc 3.3. Department of Statistics, North Carolina State University, Raleigh, North Carolina, USA.

LOWREY, T. K., AND D. J. CrAWFORD. 1985. Allozyme divergence and evolution in Tetramolopium (Compositae: Astereae) on the Hawaiian Islands. Systematic Botany 10: 64-72.

Mabberley, D. J. 1993. The plant-book: a portable dictionary of the higher plants. Cambridge University Press, Cambridge, UK.

Marrero-Gómez, M., A. Bañares-Baudet, E. Carqué-Álamo, and A. PADILLA-CUBAS. 1999. Size structure in populations of two threatened endemic plant species of the Canary Islands: Cistus osbaeckiaefolius and Helianthemum juliae. Natural Areas Journal 19: 79-86.

Martínez-Palacios, A., L. E. Eguiarte, and G. R. Furnier. 1999. Genetic diversity of the endangered endemic Agave victoriae-reginae (Agavaceae) in the Chihuahuan desert. American Journal of Botany 86: 10931098.

McCauley, D. E., J. E. Stevens, P. A. Peroni, And J. A. Raveill. 1996. The spatial distribution of chloroplast DNA and allozyme polymorphisms within a population of Silene alba (Caryophyllaceae). American Journal of Botany 83: 727-731.

Milligan, B. G., J. Leebens-Mack, And A. E. Strand. 1994. Conservation genetics: beyond the maintenance of marker diversity. Molecular Ecology 3: 423-435.

NEI, M. 1972. Genetic distance between populations. American Naturalist 106: $283-292$.

NeI, M. 1973. Analysis of gene diversity in subdivided populations. Proceedings of the National Academy of Sciences, USA 70: 3321-3323.

Pedrola-Monfort, J., and J. Caujapé-Castells. 1994. Allozymic and morphological relationships among Androcymbium gramineum, A. europaeum, and A. psammophilum (Colchicaceae). Plant Systematics and Evolution 191: 111-126.

Pérez-García, F. 1995. Germinación de semillas de Cistus osbaeckiaefolius Webb ex Christ. (Cistaceae). Botánica Macaronésica 22: 25-34.

Pleasants, J. M., AND J. F. Wendel. 1989. Genetic diversity in a clonal narrow endemic, Erythronium propulans, and its widespread progenitor Erythronium albidum. American Journal of Botany 76: 1136-1151.

RAYMOND, M., AND F. RousSET. 1995. GENEPOP (version 1.2): population genetics software for exact tests and ecumenicism. Journal of Heredity 86: 248-249.

Richter, T. S., P. S. Soltis, And D. E. Soltis. 1994. Genetic variation within and among populations of the narrow endemic, Delphinium viridescens (Ranunculaceae). American Journal of Botany 81: 1070-1076.

Rivas-Martínez, S., W. Wildpret, M. Del Arco, O. Rodríguez, P. L. Pérez, A. García, J. R. Acebes, T. E. Díaz, and F. Fernández. 1993. Las comunidades vegetales de la isla de Tenerife (Islas Canarias). Itinera Geobotanica 7: 169-374.

Santos-Guerra, A. 1999. Origen y evolución de la flora Canaria. In J. M. 
Fernández-Palacios, J. J. Bacallado, and J. A. Belmonte [eds.], Ecología y cultura en Canarias, 107-130. Museo de la Ciencia, Cabildo Insular de Tenerife, Santa Cruz de Tenerife, Canary Islands, Spain.

Schemke, D. W., B. C. Husband, M. H. Ruckelshaus, C. Goodwillie, I. M. PARKER, AND J. G. BISHOP. 1994. Evaluating approaches to the conservation of rare and endangered plants. Ecology 75: 584-606.

SCHMINCKE, H. U. 1976. The geology of the Canary Islands. In G. Kunkel [ed.], Biogeography and ecology in the Canary Islands, 67-184. Kluwer Academic, The Hague, The Netherlands.

Slatkin, M. 1985. Gene flow in natural populations. Annual Review of Ecology and Systematics 16: 393-430.

SLATKIN, M. 1987. Gene flow and the geographic structure of natural populations. Science 236: 787-792.

SlatKIN, M. 1994. Gene flow and population structure. In L. A. Real [ed.], Ecological genetics, 3-17. Princeton University Press, Princeton, New Jersey, USA.

Sosa, P. A., AND G. Garcia-ReInA. 1993. Genetic variability of Gelidium canariensis determined by isozyme electrophoresis. Journal of Phycology 29: 118-124.

STORFER, A. 1999. Gene flow and endangered species translocations: a topic revisited. Biological Conservation 87: 173-180.

SwoFford, D. L., AND R. B. SELANDER. 1981. BIOSYS-1: A FORTRAN program for the comprehensive analysis of electrophoretic data in population genetics and systematics. Journal of Heredity 72: 281-283.

SYTSMA, K. J., AND B. A. SCHAAL. 1985. Genetic variation, differentiation, and evolution in a species complex of tropical shrub based on isozymic data. Evolution 39: 582-593.
Talavera, S., P. E. GibBS, AND J. HerRera. 1993. Reproductive biology of Cistus ladanifer (Cistaceae). Plant Systematics and Evolution 186: $123-$ 134.

Templeton, A. R. 1980. The theory of speciation via the founder principle. Genetics 94: 1011-1038.

TRABaud, L., AND J. OustRic. 1989. Heat requirement for seed germination of three Cistus species in the garrigues of southern France. Flora: 321325.

Walter, K. S., AND H. J. Gillett. 1997. Red list of threatened plants. The World Conservation Union, Gland, Switzerland.

WENDEL, J. F., AND N. WEEDEN. 1989. Visualization and interpretation of plant isozymes. In D. Soltis and P. Soltis [eds.], Isozymes in plant biology, 5-44. Dioscorides, Portland, Oregon, USA.

Westerbergh, A., AND A. SAURA. 1994. Genetic differentiation in endemic Silene (Caryophyllaceae) on the Hawaiian Islands. American Journal of Botany 81: 1487-1493.

Williamson, P. S., AND C. R. WeRTH. 1999. Levels and patterns of genetic variation in the endangered species Abronia macrocarpa (Nyctaginaceae). American Journal of Botany 86: 293-301.

Witter, M. S., AND G. D. CARR. 1988. Genetic differentiation in the Hawaiian silversword alliance (Compositae: Madiinae). Evolution 42: 1278-1287.

WRIGHT, S. 1965. The interpretation of population structure by F-statistics with special regard to systems of mating. Evolution 19: 395-420.

WRIGHT, S. 1978. Evolution and the genetics of populations, vol. 4, Variability within and among natural populations. The University of Chicago Press, Chicago, Illinois, USA. 